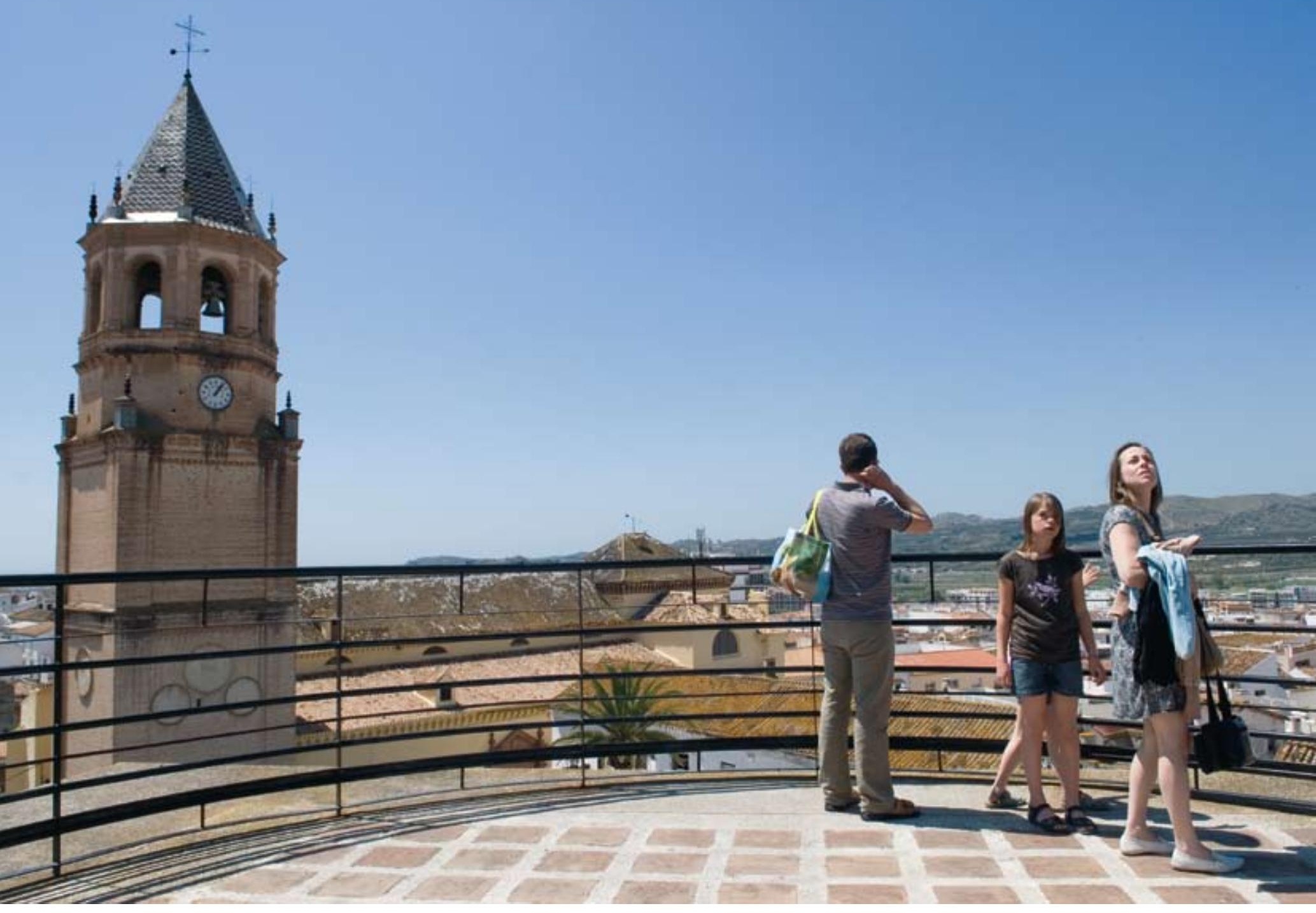

Entorno turístico de la iglesia de San Juan Bautista en Vélez-Málaga. Foto: Juan Carlos Cazalla, IAPH 


\section{Turismo y cultura}

Alfredo Rubio Díaz, Dpto. de Geografía, U. de Málaga
En la actualidad cualquier intento de comprensión de algo alcanza una cierta categoría de desmesura, ya sea por la sobreabundancia de información caracteristica de la sobremodernidad ya por la problemática implícita en las palabras. Determinar la calidad de la información y superar el vacío de las palabras se convierten casi en las labores previas, en la totalidad del ejercicio. Esa es la perspectiva de este breve artículo: el problema de abordar las relaciones entre cultura y turismo siendo ambas palabras problemáticas, siempre y cuando no nos arriesguemos a asumir su empleo vacío. Sin duda, una tercera dificultad procede de establecer la adecuada relación entre ambas y un territorio concreto: La Axarquía malagueña, las tierras del este geográfico de la provincia de Málaga.

En los países ribereños del Mediterráneo las actividades turísticas han desempeñado un importante papel en su crecimiento económico. Lentamente, tras transformar las costas, el fenómeno se ha ido expandiendo por las tierras interiores a la vez que la demanda turistica también experimentaba profundos procesos de cambio por segmentación. A partir de la década de los años noventa el "mare nostrum" se convirtió en el primer destino turístico internacional. El proceso ha sido complejo: primero estuvo reservado a una elite que actuó como prescriptora de los movimientos de masas que, tras la reconstrucción europea, iniciaron su despegue como consumidores turisticos.

El conocimiento de lo que podriamos Ilamar la fenomenología profunda del turismo de masas es esencial, es decir, cómo se ha construido un imaginario colectivo, cuyos antecedentes son diversos -desde los viajeros del siglo XVIII a los balnearios y "la invención de la playa"; desde el higienismo y la puesta a punto de los cuerpos para la producción del siglo XIX a los programas de vacaciones obreras de los fascismos europeos. Un imaginario que, en todas partes donde es posible, es construido con la ayuda de los creadores de sentido, ofreciendo un tiempo de estado de excepción en un lugar otro, que permite literalmente escapar de las condiciones de una vida insatisfactoria en los territorios de lo urbano.

En ese contexto, la mayoria de los espacios turisticos de masas del litoral de la provincia de Málaga, afectados por la produc- ción turística del territorio, han agotado su ciclo como productos turísticos e incluso sus suelos, dejando una herencia de difícil resolución. En algunos casos, hoy son territorios urbanos de la máxima complejidad. Crece en ellos el sector residencial inmobiliario sobre las cenizas de los antiguos territorios preturísticos y en la realidad de los paisajes banalizados del turismo de masas se expande la realidad de una región metropolitana (RUBIO SERRANO, 2007).

Si se entiende el turismo como una relación, aquella que ocure entre receptor y visitante, como cualquier otra requiere de una sede donde hacerla efectiva. Dicho de otro modo, será el territorio el suelo donde se haga acto. Viene todo esto al caso de La Anarquía puesto que, de algún modo, aquí la relación ha podido ser reflexionada como acondicionamiento previo de una sede a una demanda aún incipiente, al menos por comparación respecto de territorios sobre-desarrollados como la Costa del Sol Occidental. Podemos abordar esa reflexibilidad previa y preparatoria a través de un documento significativo: el Plan de Ordenación del Territorio de la Costa del Sol Occidental-Axarquía de Málaga (2006).

En su Memoria Informativa los procesos territoriales en curso se definen y diagnostican como reescritura actual de un paisaje heredado -denominado tradicional- apoyado por los procesos de crecimiento residencial tanto en el medio litoral como en el rural. Por tanto, el ámbito se encuentra en un extraordinario proceso de transformación con un buen potencial de crecimiento que requiere corregir sus principales disfuncionalidades (POT Litoral Oriental-Axarquía de Málaga, 2006: 13). Estas alcanzan un momento crítico debido a la colmatación y compactación de la franja litoral acompañado de un proceso de dispersión residencial extensiva en el interior, no reglado y en muchas ocasiones producto de parcelaciones ilegales.

Se entiende entonces que, de continuar así, podría agotar en las proximidades del litoral las posibilidades de un posible desarrollo turístico basado en el alojamiento hotelero, el cual es capaz de generar empleo y actividad de forma más intensa y durante un periodo estacional más largo (POT, 2006: 18). Este 


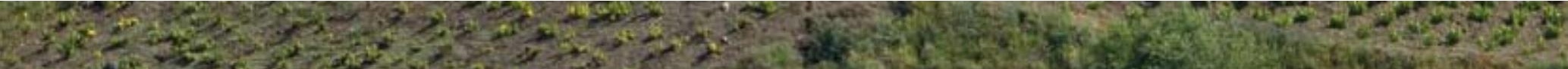

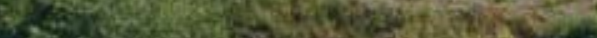

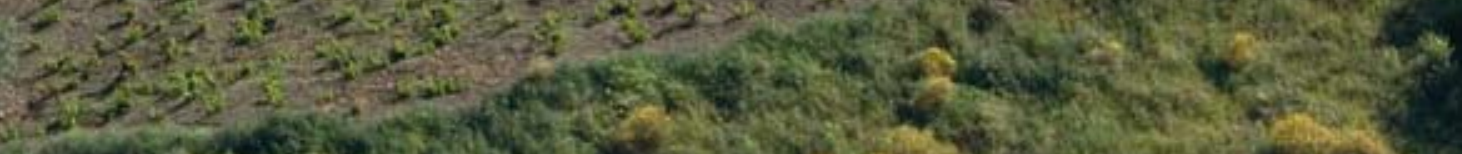

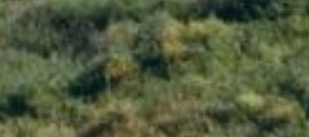

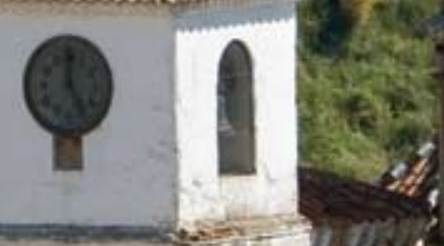

metas
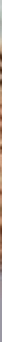


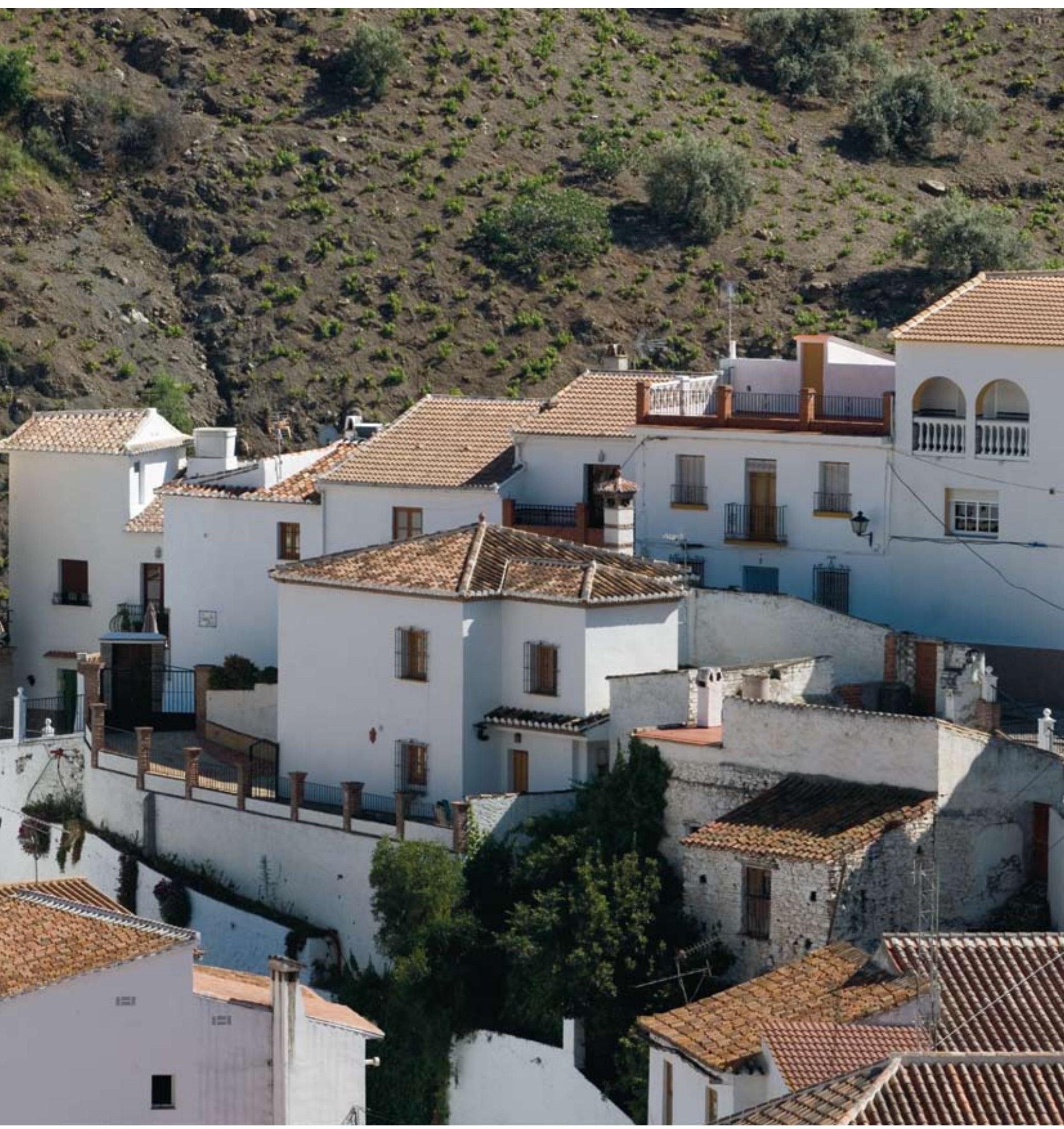


diagnóstico se completa con tres claves medioambientales: el deterioro del paisaje, el incremento de riesgos naturales y los límites del recurso agua en una cuenca deficitaria. En cierto modo, como hemos explicado en otro lugar, los costes derivados de la permanencia del "modelo" actual consisten finalmente en el deterioro de (...) los hitos paisajisticos y de formas y elementos constructivos que han dado lugar a la singularidad de su paisaje e identidad al territorio axárquico (POT, 2006: 66). Esta reducción de lo cultural a las señas de identidad paisajística (incluida la arquitectura) es lo que sirve a los redactores para justificar posteriormente las medidas de protección que se arbitran en las normas para proteger lo que denominan capital territorial (POT, 2006: 66-67).

Por tanto, la orientación del territorio serán las actividades turisticas, aunque descartando la urbanización masiva (con la excepción del litoral, como veremos), e inclinando la oferta hacia lo que denomina turismo productivo (fundamentalmente el hotelero, pero también todas aquellas actividades empresariales relacionadas con el ocio, comerciales, deportivas y recreativas, etc.), creando condiciones para que la ordenación urbanistica configure espacios bien ordenados y de calidad urbana y ambiental (POT, 2005: 80). Por otra parte, las referencias en el "Diagnóstico" a las economias productivas son muy reducidas, cuando no inexistentes $y_{1}$ por lo que se refiere a las logísticas e industriales se supone que crecerán vinculadas a la expansión de la aglomeración urbana de Málaga (POT, 2006: 33).

Esta orientación suscita una primera cuestión: la mirada planificadora no ha encontrado nada más que el paisaje en la potencia del territorio. Parece tanto una mirada cansada, que no es capaz de dar cuenta de la potencia, que se adscribe a las manifestaciones formales (de una sociedad y su cultura), como interferida por un a priori que hace imposible ver otra cosa. Según el Plan, en La Axarquía no parece existir otro impulso posible. Visto así, lo eficaz será transferir a la "valiosa identidad comarcal" el valor de dimensión competitiva (POT, 2005: 63) dado que, los productos turísticos basados en la "experiencia" -se enfatiza- y en los ingredientes singulares del destino tienen una aceptación creciente, y La Axarquia dispone ahi de un caudal potencial decisivo siempre y cuando, se reitera, se modulen las tendencias propias del mercado, aprovechando la energía que proporciona la demanda con el fin de lograr los objetivos fijados en este Plan de Ordenación del Territorio. El modelo que se propugna pretende que, junto a un aprovechamiento ordenado de la oportunidad de crecimiento, se conserve y se incremente el capital del territorio, tanto el de carácter natural, como el cultural e identitario (POT, 2006: 64).

Se hace un recuento exhaustivo de los diversos elementos que deben ordenarse de acuerdo con esa intención, que en conjunto integran lo que se define como espacio turístico comarcal (POT, 2006: 80). Todo esto supone la mayor parte de la extensión territorial de la comarca, pues sólo quedan al margen lo ocupado por la actividad industrial y logistica, las infraestructuras, las áreas de regadio y los asentamientos de primera residencia no afectados por protecciones de carácter histórico, cultural o paisajístico, es decir una superficie que no llega al 10\% del total. De todos los usos contemplados sólo se promueve el crecimiento de los turísticos; en concreto (...) la expansión de los alojamientos turisticos y la oferta de servicios empresariales (artículo 39.2 a), así como el (...) crecimiento ordenado de el sector turistico en el frente del litoral (artículo 39.2 c) y establecer las condiciones para el desarrollo del sector turistico en el interior de La Axarquía (artículo 39.2 d).

Además el Plan prevé las Zonas de Oportunidad para Actividades Comerciales y de Ocio (POT, 2005: 116), y con una intencionalidad más clara las Zonas de Dinamización Turistica destinadas al asiento de actividades del turismo "productivo" capaces de funcionar durante toda la anualidad. Estas proceden, en su mayor parte, de reservas territoriales que se realizaron a mediados de los años ochenta por protección paisajista del espacio productivo agrario y que en el momento presente han perdido su sentido y su justificación, por una parte, una vez desaparecido el cultivo de la caña de azúcar, que les dotaba de una identidad singular y, por otra, debido a las transformaciones acaecidas que, o bien ha dado lugar al abandono de las actividades agrícolas (regadíos tradicionales), su sustitución en ciertos casos (invernaderos) o permanecen improductivos, en todo caso, conformando espacios sin valores paisajísticos de interés.

De hecho estamos ante una operación de "clasificación urbanistica" (afín a la de "suelo urbanizable") directa por parte del Plan, la cual, por cierto, contribuye a una mayor colmatación urbana de la franja litoral. Pero las consecuencias no se limitan a esto: el hecho de que el POT juzgue estos terrenos como de escaso valor paisajístico no quiere decir que no puedan adquirirlo mediante su oportuna conversión en espacios libres, por ejemplo, y un tratamiento adecuado. Sin embargo esa posibilidad aparentemente ha cedido ante los intereses del mayor propietario de suelo en el litoral de la comarca, justificando la decisión adoptada por la necesidad de prever espacios concretos para cubrir ese déficit de oferta turística empresarial tantas veces esgrimido.

Con la perspectiva de los intereses generales esta elección es discutible, especialmente por lo que respecta a dos de estas zonas de dinamización turistica, las que ocupan los espacios litorales mayores que todavía permanecen relativamente libres: en la playa del Hornillo, al oeste de Torre del Mar, y el Playazo, a poniente del núcleo de Nerja. Estas dos operaciones reducirán los frentes de playa libres de la comarca, es decir, no ocupados por suelos urbanos o urbanizables al 5\% del total, con el argumento de su no identidad (RUBIO; SERRANO, 2007).

Suponiendo que lo anterior es una breve descripción transparente de lo que el POT supone podemos entrar ya más directamente en las cuestiones que nos ocupan. 

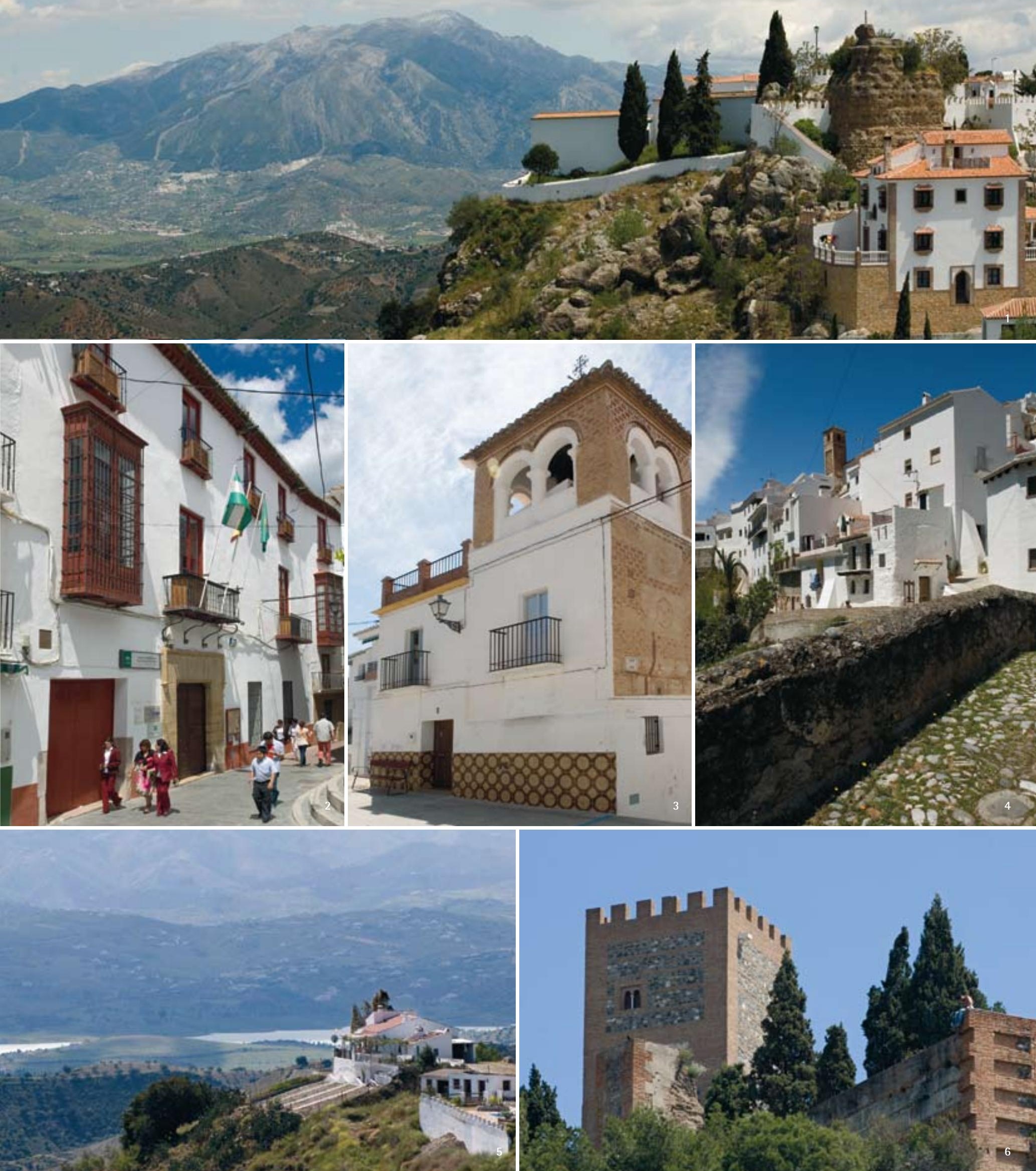

1. El castillo de Comares domina un paisaje de barrancos y montañas

2. Casa Cervantes en Vélez-Málaga

3. Arquitectura tradicional en Sedella

Fotos: Juan Carlos Cazalla, IAPH

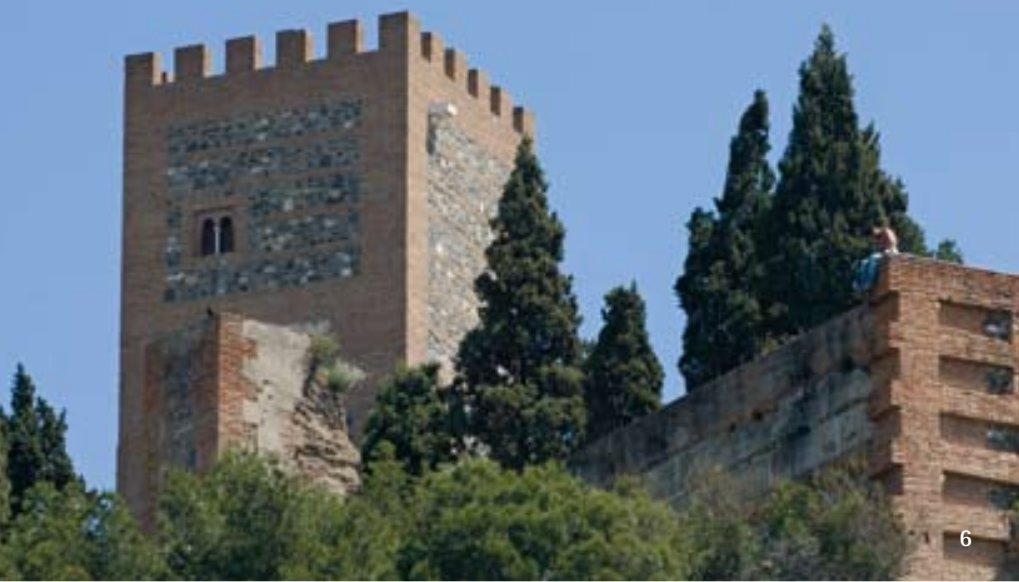

4. Vista de Salares desde el puente árabe

5. Paisaje desde Canillas de Aceituno

6. Castillo de Vélez-Málaga

Fotos: Juan Carlos Cazalla, IAPH 
El paisaje interior actual de La

Axarquía no es exactamente

un paisaje rural vivo, con una

población actuante como tal, puesto que la mayoría trabaja fuera

de La Axarquía interior

El territorio no puede ser explicado sin considerarlo también como proceso (y de ahi lo decisivo de comprender que la población es parte integrante del mismo), ni la cultura puede ser reducida a sus manifestaciones materiales, tampoco la belleza y la singularidad de un paisaje pueden ser mantenidas con simples disposiciones de un control puramente defensivo. El paisaje está vivo y tratar de congelarlo es prácticamente la misma operación que la tematización de ciertos espacios de la ciudad histórica. Pero, en este caso, al hacerse abstracción de los procesos culturales y sociales, ya no solamente acumulativos (y previsibles) sino también de los no previsibles (el cambio), lo único que se conseguirá es mantener el espejismo de un determinismo impuesto desde fuera y desde arriba.

El problema de fondo que aqui aparece es precisamente el de objetivar la transformación global de un territorio en un producto turístico "productivo" y que se habilita como "alternativo" cuando, y los estudios e investigaciones son muy abundantes, el turismo como actividad tiene la capacidad de readaptar la naturaleza y la cultura a sus propias necesidades (MACCANNELL, 2007: 11) y, lo que es peor, tiende a eliminar precisamente aqueIlo que lo desencadenó (HARVEY; SMITH, 2005: 32-33). Probablemente la mirada planificadora se ha enfrentado a las consecuencias acumuladas de los cercanos procesos (la Costa del Sol Occidental) buscando una salida alternativa. Sin embargo, no ha estudiado sus patrones: por ejemplo, los procesos posteriores a una fase inicial basada en la oferta hotelera de calidad, como sucedió en los casos de los municipios de Torremolinos, Benalmádena Costa y Marbella, se fundamentaron en un elemento de causalidad circular y acumulativa dando lugar a las actuales condiciones de hacinamiento constructivo. También parece ignorar que la construcción de un producto turístico, basado en la personalización del territorio como poseedor de una identidad, significa necesariamente su inserción en el ciclo de producto. En resumen, el territorio no se entiende en su singularidad irreducible, en su potencia propia de ser alguna otra cosa que sea distinta de lo heredado o de su degradación actual.

En este sentido, cabe preguntarse qué significa el concepto de "paisaje tradicional" en La Axarquía, cuando se pueden construir sin grandes dificultades cinco secuencias fundamentales en su proceso hasta llegar a la situación actual. El paisaje interior actual de La Axarquía no es exactamente un paisaje rural vivo, con una población rural actuante como tal, puesto que la mayoria trabaja fuera de La Axarquía interior. Donde, además, se insertan tanto el fenómeno de las urbanizaciones ilegales (unas veinte mil casas) que lentamente van transformando el paisaje que se desea conservar, pues (...) es precisamente la belleza de este paisaje el factor principal de su deterioro (POT, 2006: 12), como los distintos efectos de su pertenencia al área metropolitana de Málaga (suburbanización).

La preservación de las construcciones y demás elementos ligados al cultivo de secano tradicional, la función del cultivo del olivar como puro elemento (ornamento) constitutivo del paisaje para una economía, otra que la propia de lo rural, el férreo mantenimiento de la escala y extensión de los núcleos de población y toda una larga serie de medidas preservadoras significan la congelación del paisaje y con ello de la vida social y de la cultura implícita en la misma. Se propone una gigantesca escenografía donde una población está obligada a cumplir con una identidad construida desde un exterior para conseguir mantener inalterable un supuesto paisaje tradicional (una herencia dudosa como tarea). En realidad, lo que se perfila es un territorio donde el litoral actuará como receptor de un segmento turístico consumidor del binomio paisaje-cultura, alojado en hoteles acaso con encanto, y un interior cristalizado donde dichos turistas podrán vivir una experiencia a través de circuitos, rutas, sendas y "miradores".

El POT pretende evitar los más perniciosos efectos de una ocupación ahora descontrolada del medio rural; pero se trata de prohibiciones o limitaciones que no están acompañadas de otro tipo de soluciones, más profundas y capaces de articular otras opciones productivas, con el turismo como una actividad ponderada. Aplica medidas "formales" en los dos sentidos de la palabra: que atañen a la apariencia de lo que se construye y de la consecuente afectación del entorno territorial; y por otro lado formal, en el sentido de reglado, de lo que por su naturaleza jurídica sólo incide sobre los efectos de conductas sobre cuyas causas o motivaciones bien poco se informa.

Una complejidad fantástica caracteriza este territorio, lo que explica su singularidad. Preferimos esta palabra a la de identidad dado que esta remite a una condición de clausura y acabamiento, mientras que lo singular, en nuestra acepción, está siempre abierto y es creativo. Se debe recordar que, no siendo sujeto, el paisaje no puede encarnar exactamente una identidad. Con todo, el paisaje como exterioridad producida por una cultura, cristalizado como se pretende, y obligado indirectamente a repetirse a si mismo, pues sólo es producto y percepción de lo humano, excluye lo común. Dicha exclusión significa imposibilidad de uso tanto para habitantes como para turistas. 